\title{
A Novel Zero-Current Soft-Switching Converter for Switched Reluctance Motor Drives
}

\author{
K.T. Chau, T.W. Ching, C.C. Chan and Marco S.W. Chan \\ Department of Electrical \& Electronic Engineering \\ The University of Hong Kong \\ Pokfulam, Hong Kong, China \\ ktchau@eee.hku.hk
}

\begin{abstract}
A new zero-current-transition (ZCT) converter for switched reluctance motor drives is presented. The proposed ZCT converter possesses the definite advantages that both the main and auxiliary switches are operating with zero-current switching (ZCS), as well as minimum current and voltage stresses. It has simple circuit topology, minimum component count and low cost. The ZCT technique can significantly reduce the switch on or off losses by forcing the current to zero prior to its turn-on or turnoff. The proposed converter is especially advantageous for switched reluctance motor (SRM) drives demanding efficient regenerative braking, such as electric vehicle application.
\end{abstract}

\section{INTRODUCTION}

The switched reluctance motor (SRM) drive is a kind of brushless motor drives, without any rotor conductors nor permanent magnets. The SRM operates on the force of magnetic attraction with the simplest configuration compared with the other types of brushless motors. The SRM drive has some definite advantages for electric vehicle propulsion - simplest and most reliable construction, high efficiency over wide speed and torque ranges, high starting torque and low starting power, fully controllable fourquadrant operation and fast dynamic response.

Within the last decade, the research and development on SRM drives have been focused on the motor topology design and optimization as well as the motor control strategies. Nevertheless, a number of converter topologies for SRM drives have also been proposed [1]. However, most of these converter topologies employ the hardswitching technique which causes high switching losses and severe electromagnetic interference (EMI).

Recently, a number of soft-switching techniques, providing zero-voltage switching (ZVS) or zero-current switching (ZCS) condition, have been successfully developed for switched-mode power supplies (SMPS) [2][7]. Surprisingly, the development of soft-switching converters for dc and SRM drives has been very little. Even so, it has been assumed that those being developed for SMPS can be directly applicable. Until recently, a few studies on soft-switching converters for $\mathrm{dc}$ and SRM drives have been carried out [8]-[11].

In this paper, a new zero-current-switching pulse-widthmodulated (ZCT-PWM) so called zero-current-transition (ZCT) converter, is proposed for SRM drives. Its principle of operation and simulation results will be given. It possesses some definite advantages over its PWM counterpart and other soft-switching converters, namely both the main and auxiliary switches can operate with ZCS as well as minimum voltage and current stresses. It has simple circuit topology, minimum hardware count, and low cost, leading to achieve high switching frequency, high power density and high efficiency. The ZCT technique can significantly reduce the switch on or off losses by forcing the current to zero prior to its turn-on or turnoff. The proposed topology is very suitable for SRM drives using insulated gate bipolar transistors (IGBTs), MOS-controlled thyristors (MCTs) or gate-turnoff thyristors (GTOs) as power devices. Since these power devices generally suffer from severe inductive turnoff losses, they prefer ZCS to ZVS.

Fig. 1 shows the circuit diagram of a conventional hardswitching $(n+1)$-switch converter for SRM drives. The upper chopping switch $S_{m}$ serves all three phases while the lower commutating switches $S_{1}, S_{2}$ and $S_{3}$ commutate the phases by selecting one phase at a time sequentially. For example, in Fig. 2(a), phase-1 is selected by turning on $S_{1}$ and the phase-1 current is controlled by switching $S_{m}$. After a desired time, in Fig. 2(b), $S_{m}$ is turned off and the phase-1 current is freewheeling by $D_{m}$. Then, in Fig. 2(c), $S_{1}$ is turned off and energy returns to the source through $D_{m}$ and $D_{1}$. The SRM can be operated at regeneration simply by retarding the firing angles in such a way that the phase winding conduction period comes after the aligned position.

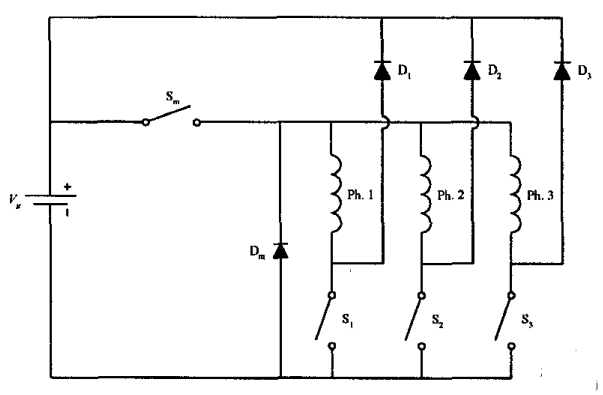

Fig. 1. Conventional converter for SRM drives.

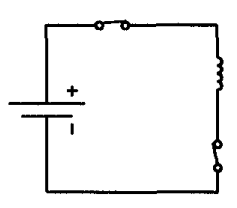

(a)

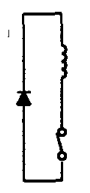

(b)

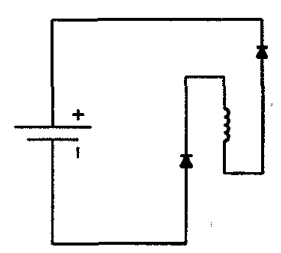

(c)
Fig. 2. Conduction modes for one phase. 


\section{MODES OF OPERATION}

\section{A. Single-Pulse Mode}

In the single-pulse mode, phase flux builds from zero during each stroke. The supply voltage turns on at the turn-on angle $\theta_{O}$, and current begins to rise as the rotor poles approach the stator poles of the next phase to be excited. The supply then turns off at the commutation angle $\theta_{C}$.

\section{B. Voltage PWM Mode}

1) Voltage PWM - Soft Chopping Mode: Soft chopping involves turning on $\mathrm{S}_{1}$ for the full period between $\theta_{0}$ and $\theta_{C}$, and turning $\mathrm{S}_{\mathrm{m}}$ on and off at a high frequency with a fixed duty cycle during the same period. When $S_{m}$ is on, the supply voltage is connected to the phase winding. When it is off, the winding is short-circuited through $\mathrm{S}_{1}$ and $D_{m}$.

2) Voltage PWM - Hard Chopping Mode: In hard chopping, both $S_{m}$ and $S_{1}$ are switched together at high frequency.

\section{Current-Regulated Chopping}

It uses a current regulator and reference source to switch the power switches on and off. Both soft and hard chopping schemes are possible. A simple hysteresis controller maintains the current magnitude within an upper and lower limit. As the supply voltage is fixed, the result is that the switching frequency decreases as the incremental inductance of the phase winding increases.

\section{PRINCIPLE OF OPERATION OF ZCT-SRM DRIVES}

To achieve ZCT operation, two resonant tanks are added to form the proposed ZCT converter for SRM drives shown in Fig. 3. A resonant inductor $L_{a}$, a resonant capacitor $C_{a}$, an auxiliary switch $S_{a}$ and a diode $D_{a}$ are added to the chopping switch $S_{m}$. A resonant inductor $L_{b}$, a resonant capacitors $C_{b}$, a diode $D_{b}$, and four auxiliary switches $S_{b}$ and $S_{b 1-3}$ are added to the commutating switches $S_{1-3}$.

A simplified one-phase circuit diagram is shown in Fig. 4. $S_{m}, D_{m}, V_{g}$ and the phase winding can be treated as a buck converter while $S_{1}, D_{1}, V_{g}$ and the phase winding can be treated as a boost converter. The equivalent circuits and operating waveforms are shown in Figs. 5 to 8, respectively.

It should be noted that although the necessary hardware component for achieving the ZCT operation is similar to that for zero-voltage transition (ZVT), their hardware configurations, principles of operation, equivalent circuits as well as operating waveforms and characteristics are very different. As shown in Figs. 5 and 7, there are nine operating stages within one switching cycle, which are briefly described as follows.

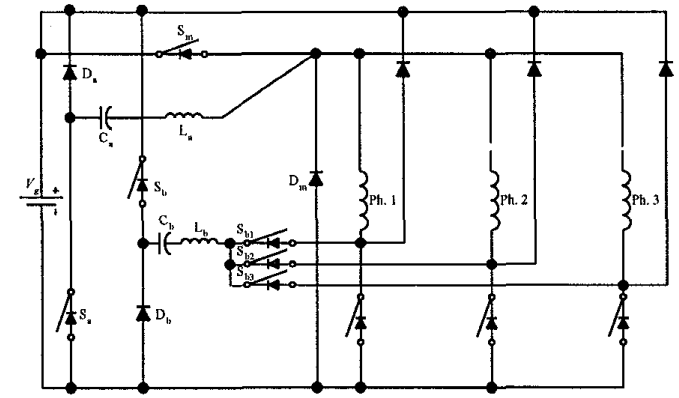

Fig. 3. Proposed ZCT converter for SRM drives.

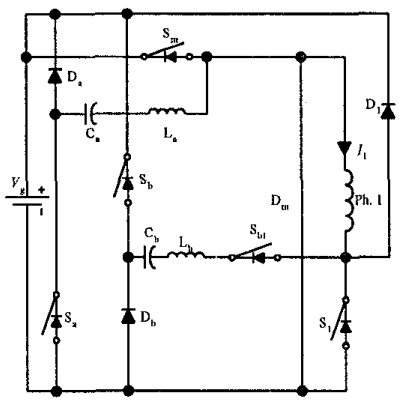

Fig. 4. Simplified one-phase circuit diagram.

\section{A. ZCT Operation of $S_{m}$ with $L_{a}, C_{a}, S_{a}$ and $D_{a}$. (Figs. 5 and 6)}

(a) Stage $1\left[T_{0}-T_{1}\right]: \quad \mathrm{S}_{\mathrm{a}}$ is turned on and $\mathrm{L}_{\mathrm{a}}$ and $\mathrm{C}_{\mathrm{a}}$ start resonating. When $i_{L_{a}}$ increases from zero to peak and then decreases toward zero and changes direction. $i_{L_{a}}$ reaches $-I_{1}$ at $T_{1}$ and the antiparallel diode of $\mathrm{S}_{\mathrm{a}}$ becomes on.

(b) Stage $2\left[T_{1}-T_{2}\right]: \quad S_{a}$ is turned off and $S_{m}$ is turned on with ZCS at $T_{1}$. The current of $\mathrm{D}_{\mathrm{m}}$ is directed to the auxiliary circuit. $i_{L_{a}}$ increases rapidly towards zero.

(c) Stage $3\left[T_{2}-T_{3}\right]: \quad i_{L_{a}}$ returns to zero at $T_{2}$ and the antiparallel diode of $\mathrm{S}_{\mathrm{a}}$ is turned off naturally. $\mathrm{L}_{\mathrm{a}}$ and $\mathrm{C}_{\mathrm{a}}$ continue resonating and the positive $i_{L_{a}}$ is conducted by $\mathrm{D}_{\mathrm{a}} \cdot i_{L_{a}}$ returns to zero and $\mathrm{D}_{\mathfrak{a}}$ is turned off naturally at $T_{3}$.

(d) Stage $4\left[T_{3}-T_{4}\right]$ : It is a powering mode.

(e) Stage $5\left[T_{4}-T_{5}\right]$ : Before $\mathrm{S}_{\mathrm{m}}$ is turned off, $\mathrm{S}_{\mathrm{a}}$ is turned on again. $\mathrm{L}_{\mathrm{a}}$ and $\mathrm{C}_{\mathrm{a}}$ start resonating. When $i_{L_{a}}$ increases from zero to peak and then decreases toward zero and changes direction and reaches $-I_{1}$ at $T_{5}$ and the antiparallel diode of $\mathrm{S}_{\mathrm{a}}$ becomes on.

(f) Stage $6\left[T_{5}-T_{6}\right]$ : At $T_{5}, i_{L_{a}}$ reaches $-I_{1}$ and the current of $S_{m}$ is reduced to zero, so $S_{m}$ is turned off with ZCS. As $i_{L_{a}}$ keeps decreasing, and flows through the antiparallel diode of $S_{m}$. 
(g) Stage $7\left[T_{6}-T_{7}\right]$ : At $T_{6}, i_{L_{a}}$ reaches to $-I_{1}$ and the antiparallel diode of $S_{m}$ stops conducting.

(h) Stage $8\left[T_{7}-T_{8}\right]$ : At $T_{7}, v_{C_{a}}$ is discharged to zero and $\mathrm{D}_{\mathrm{m}}$ starts to conduct. The current in $\mathrm{D}_{\mathrm{m}}$ increases gradually.

(i) Stage $9\left[T_{8}-T_{9}\right]:$ It is a freewheeling mode via $\mathrm{D}_{m}$.

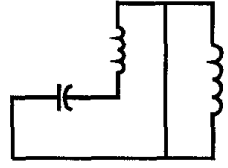

(a)

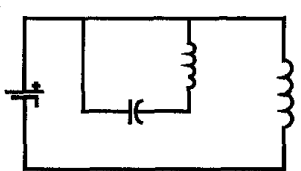

(c)

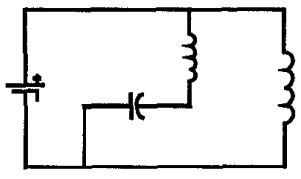

(e)

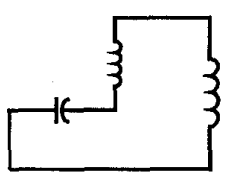

(g)

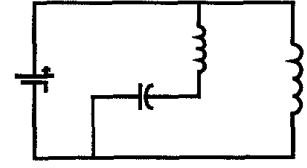

(b)

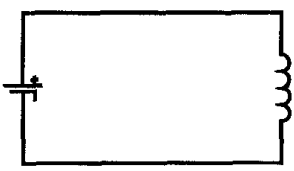

(d)

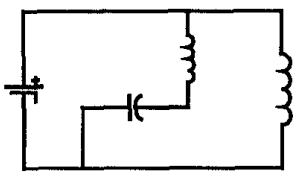

(f)

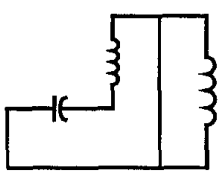

(h)

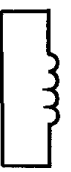

(i)

Fig. 5. Equivalent circuit for ZCT operation of $S_{m}$.

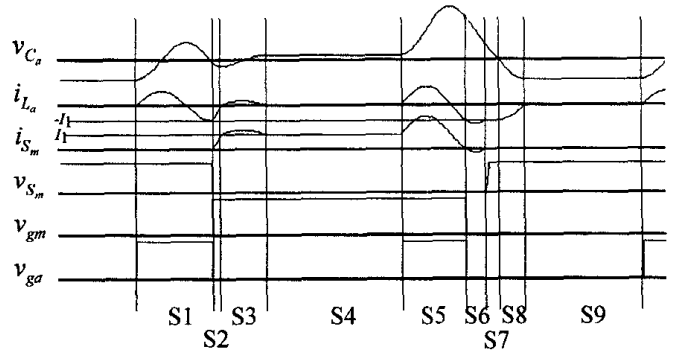

Fig. 6. Key waveforms for $S_{m}$.
B. ZCT Operation of $S_{1}$ with $L_{b}, C_{b}, S_{b}$ and $S_{b 1}$. (Figs. 7 and 8)

(a) Stage $1\left[T_{0}-T_{1}\right]: \quad \mathrm{S}_{\mathrm{b}}$ and $\mathrm{S}_{\mathrm{b} 1}$ are turned on and $\mathrm{L}_{\mathrm{b}}$ and $\mathrm{C}_{\mathrm{b}}$ start resonating. When $i_{L_{b}}$ decreases from zero to negative peak and then increases toward zero and changes direction. $i_{L_{b}}$ reaches $I_{1}$ at $T_{1}$ and the antiparallel diode of $S_{b}$ and $S_{b 1}$ become on.

(b) Stage $2\left[T_{1}-T_{2}\right]: \quad \mathrm{S}_{\mathrm{b}}$ and $\mathrm{S}_{\mathrm{b} 1}$ are turned off and $\mathrm{S}_{1}$ is turned on with ZCS at $T_{1}$. The current of $\mathrm{D}_{1}$ is directed to the auxiliary circuit. $i_{L_{b}}$ decreases rapidly towards zero.

(c) Stage $3\left[T_{2}-T_{3}\right]: \quad i_{L_{b}}$ returns to zero at $T_{2}$ and the antiparallel diode of $S_{b}$ and $S_{b 1}$ are turned off naturally. $\mathrm{L}_{b}$ and $\mathrm{C}_{\mathrm{b}}$ continue resonating and the negative $i_{L_{b}}$ is conducted by $\mathrm{D}_{\mathrm{b}}$ and $\mathrm{D}_{\mathrm{b} 1} \cdot i_{L_{b}}$ returns to zero and $\mathrm{D}_{\mathrm{b}}$ and $\mathrm{D}_{\mathrm{b} 1}$ are turned off naturally at $T_{3}$.

(d) Stage $4\left[T_{3}-T_{4}\right]$ : It is a freewheeling mode.

(e) Stage $5\left[T_{4}-T_{5}\right]$ : Before $\mathrm{S}_{1}$ is turned off, $\mathrm{S}_{\mathrm{b}}$ and $\mathrm{S}_{\mathrm{b} 1}$ are turned on again. $L_{b}$ and $C_{b}$ start resonating. When $i_{L_{b}}$ decreases from negative zero to peak and then increases toward zero and changes direction and reaches $I_{1}$ at $T_{5}$ and the antiparallel diode of $\mathrm{S}_{\mathrm{b}}$ and $\mathrm{S}_{\mathrm{b} 1}$ become on.

(f) Stage $6\left[T_{5}-T_{6}\right]:$ At $T_{5}$ reaches $I_{1}$ and the current of $S_{1}$ is reduced to zero, so $S_{1}$ is turned off with ZCS. As $i_{L_{b}}$ keeps increasing, and flows through the antiparallel diode of $S_{1}$.

(g) Stage $7\left[T_{6}-T_{7}\right]$ : At $T_{6}, i_{L_{b}}$ falls to $I_{1}$ and the antiparallel diode of $S_{1}$ stops conducting.

(h) Stage $8\left[T_{7}-T_{8}\right]: \quad$ At $T_{7}, v_{C_{b}}$ is discharged to zero and $D_{1}$ starts to conduct. The current in $D_{1}$ increases gradually.

(i) Stage $9\left[T_{8}-T_{9}\right]$ : It is a powering mode via $D_{1}$.

\section{SIMULATION RESULTS}

Different modes of operation of the proposed ZCT converter for SRM drives are PSpice-simulated, results are shown in Figs. 9 to 12.

Fig. 9 shows the simulated waveforms of the proposed converter operating in single-pulse mode. The supply voltage turns on at the turn-on angle $\theta_{O}$, and then turns off at the commutation angle $\theta_{C}$.

Operating waveforms of voltage PWM - soft chopping mode is shown in Fig. 10. $S_{1}$ is turned on for the full period between $\theta_{O}$ and $\theta_{C}$, and $\mathrm{S}_{\mathrm{m}}$ is turned on and off at a high frequency with a fixed duty cycle during the same period. 
Fig. 11 shows the operating waveforms of the ZCT converter operating in voltage PWM - hard chopping mode. Both $S_{m}$ and $S_{1}$ are switched together at high frequency.

For Fig. 12, a hysteresis controller is used to maintain the current magnitude within and upper and lower limit for the simulation of the proposed converter to operate in current-regulated soft chopping mode.

From Figs. 9 to 12, the simulated results agree with those theoretical waveforms. The main and auxiliary switches of the proposed ZCT converter $\left(\mathrm{S}_{\mathrm{m}}, \mathrm{S}_{\mathrm{a}}, \mathrm{S}_{1}, \mathrm{~S}_{\mathrm{b}}\right.$ and $\left.\mathrm{S}_{\mathrm{b} 1}\right)$ can always operate with ZCS.

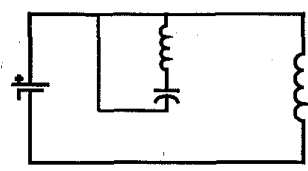

(a)

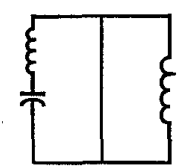

(c)

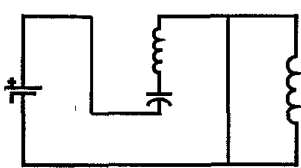

(e)

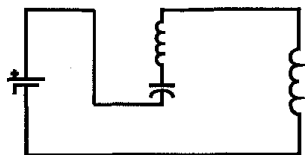

(g)

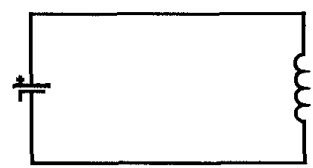

(i)

Fig. 7. Equivalent circuit for ZCT operation of $S_{1}$.

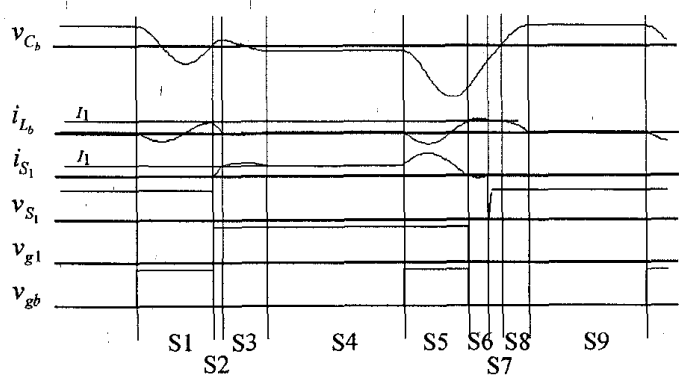

Fig. 8. Key waveforms for $S_{1}$.

\section{CONCLUSION}

A new ZCT converter for SRM drives has been presented. The ZCT converter possesses the definite advantages that both the main and auxiliary switches can always maintain ZCS with minimum current and voltage stress, as well as it can be implemented with a simple circuit topology, minimum hardware count and low cost, leading to achieve high power density and high efficiency.

\section{ACKNOWLEDGMENT}

This work was supported and funded in part by the Committee on Research and Conference Grants in the University of Hong Kong, and the Hong Kong Research Grants Council.

\section{REFERENCES}

[1] T.J.E. Miller, Switched Reluctance Motors and Their Control, Oxford Science Publications, 1993.

[2] D. Maksimovic and S. Cuk, "Constant-frequency control of quasi-resonant converters," IEEE Trans. Power Electronics, vol. 6, 1991, pp. 141-150.

[3] C.C. Chan and K.T. Chau, "A new zero-voltageswitching dc/dc boost converter," IEEE Trans. Aerospace and Electronic Systems, vol. 29, 1993, pp. 125-134.

[4] G. Hua, C.S. Leu and F.C. Lee, "Novel zero-voltagetransition PWM converters," In Proc. of VPEC Seminar, 1991, pp. 81-88.

[5] J.G. Cho, J.W. Baek, G.H. Rim and I. Kang, "Novel zero voltage transition PWM multi-phase converters," In Proc. of IEEE APEC, 1996, pp. 500506.

[6] H. Mao, F.C.Y. Lee, X. Zhou, H. Dai, M. Cosan and D. Boroyevich, "Improved zero-current transition converters for high power applications," IEEE Trans. Industry Applications, vol. 33, 1997, pp. 1220-1231.

[7] K.T. Chau, "A new class of pulsewidth-modulated multi-resonant converters using resonant inductor freewheeling," Int. Journal of Electronics, vol. 77, 1994, pp. 703-714.

[8] K.T. Chau, T.W. Ching and C.C. Chan, "Constantfrequency multi-resonant converter-fed dc motor drives," In Proc. of IEEE IECON, 1996, pp. 78-83.

[9] K.T. Chau, T.W. Ching, C.C. Chan and T.W. Chan, "A novel soft-switching two-quadrant converter for dc motor drives," In Proc. of IEEE IECON, 1997, pp. 517-522.

[10] Y. Murai, J. Cheng, and M. Yoshida, "A softswitched reluctance motor drives circuit with improved performances," In Proc. of IEEE PESC, 1997, pp. 881-886.

[11] J.G. Cho, W.H. Kim, G.H. Rim and, K.Y. Cho, "Novel zero transition PWM converter for switched reluctance motor drives," In Proc. of IEEE PESC, 1997, pp. 887-891. 


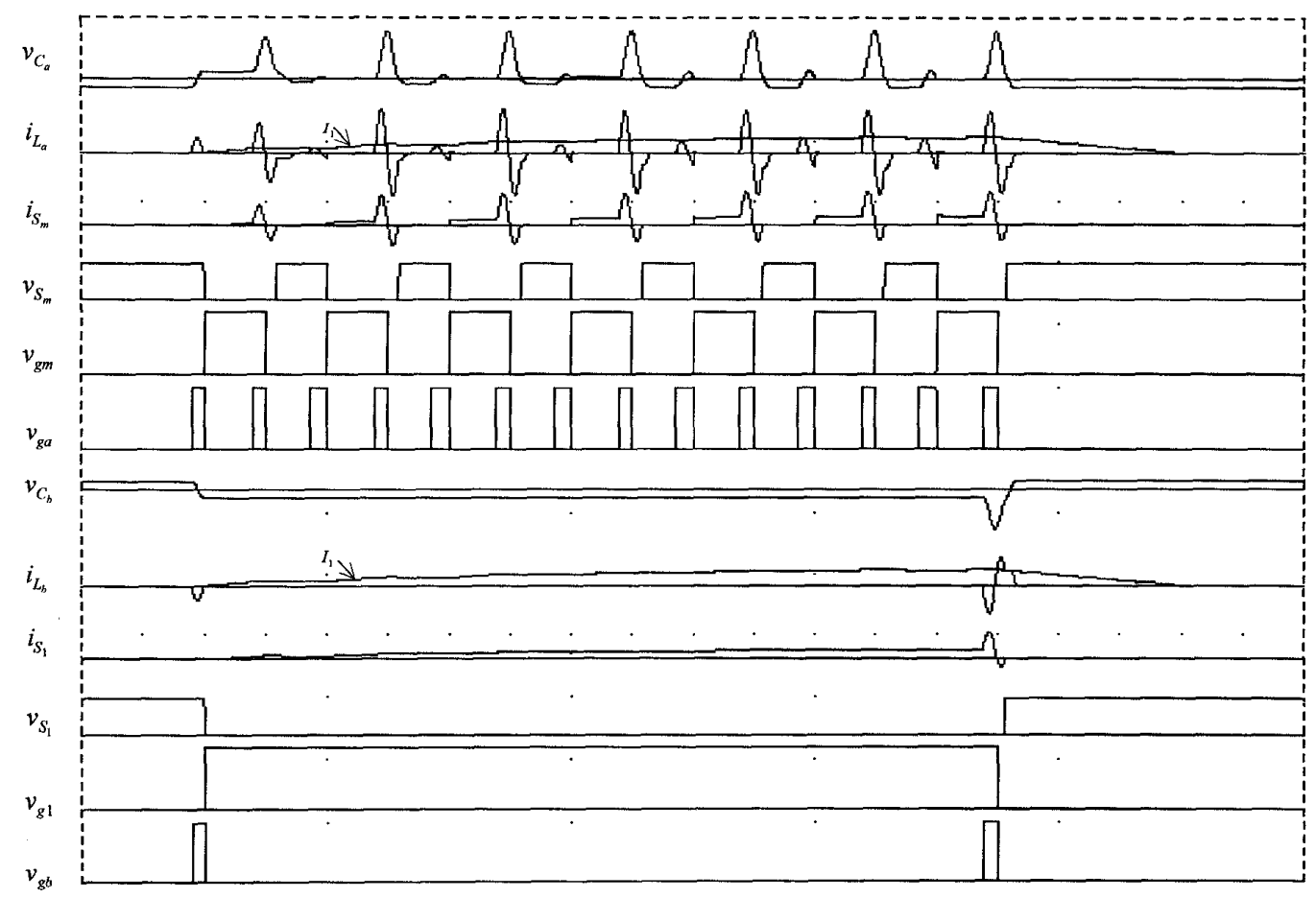

Fig. 9. PSpice simulation showing key waveforms of the ZCT converter (Single-pulse mode).

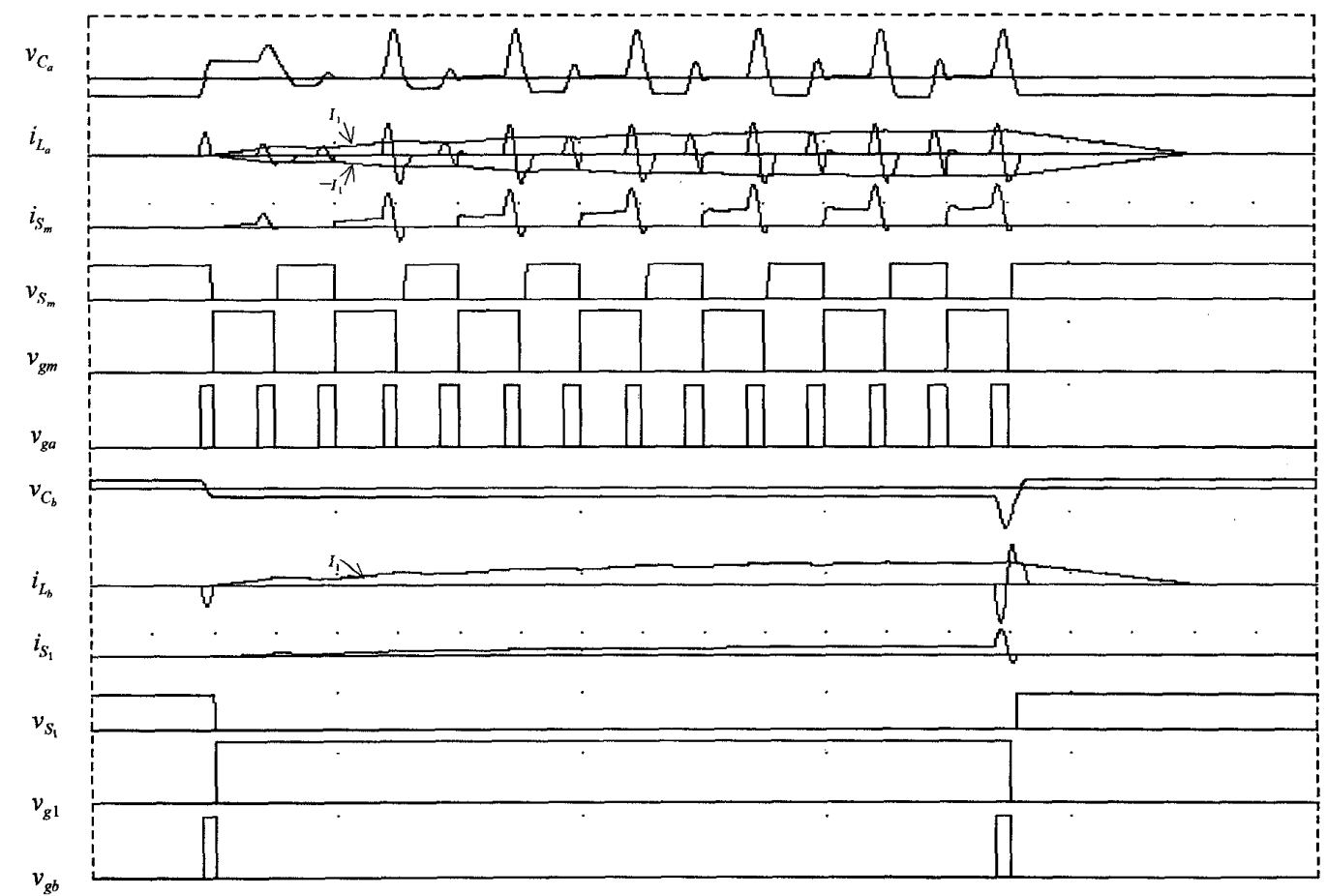

Fig. 10. PSpice simulation showing key waveforms of the ZCT converter (Voltage PWM - soft chopping mode). 


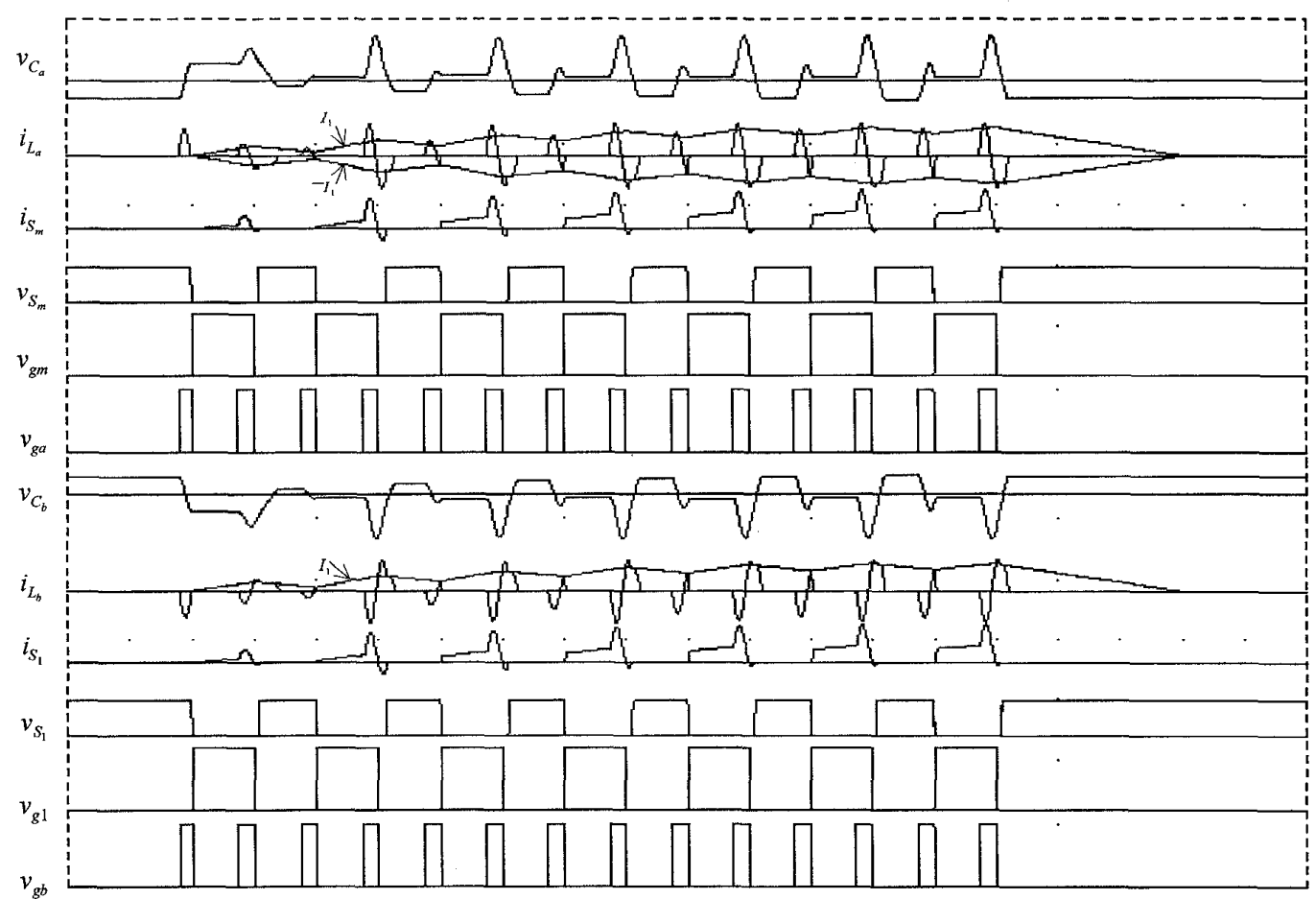

Fig. 11. PSpice simulation showing key waveforms of the ZCT converter (Voltage PWM - hard chopping mode).

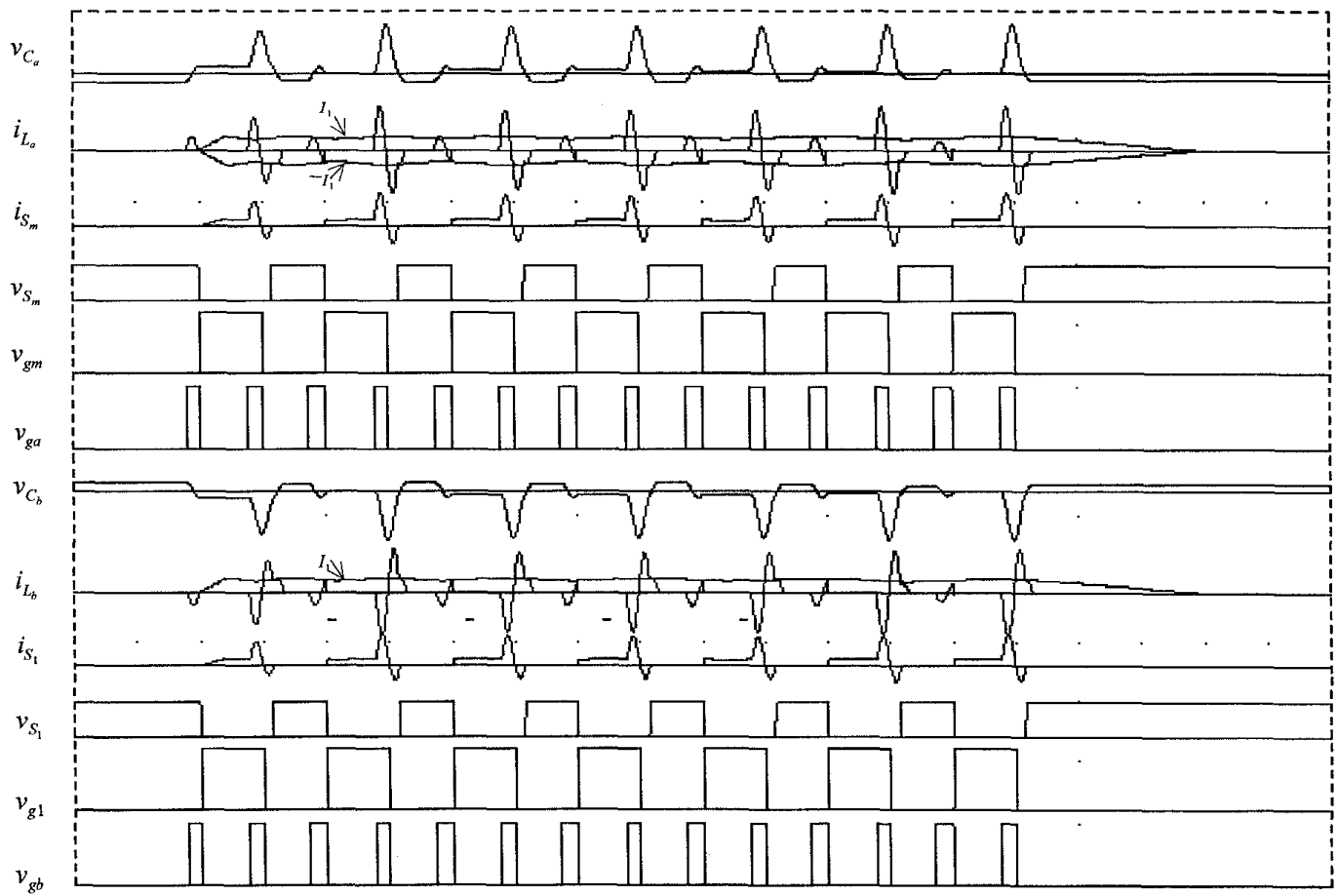

Fig. 12. PSpice simulation showing key waveforms of the ZCT converter (Current regulation - soft chopping mode). 